\title{
The Synthesis of $\boldsymbol{p}$-Aminobenzoic Acid and Folic Acid by Staphylococci Sensitive and Resistant to Sulphonamides
}

\author{
By P. J. WHITE* and THE LATE D. D. WOODS \\ Microbiology Unit, Department of Biochemistry, University of Oxford
}

(Received 26 February 1965)

\section{SUMMARY}

The synthesis of $p$-aminobenzoic acid and folic acid was investigated in three strains of Staphylococcus sensitive to sulphonamide drugs, and in four substrains resistant to sulphonamides. Another strain (Staphylococcus aureus $\mathbf{R} 122$ ) which was resistant to sulphonamides when isolated was also examined. A microbiological assay was used to measure the synthesis of $p$-aminobenzoic acid during the growth of organisms in a partially defined medium. $S$. aureus $\mathrm{R} 122$ formed about twenty times as much $p$-aminobenzoic acid as did any of the other strains, among which the synthesis showed only small variations and was not greatly affected by growth of the organisms in presence of sulphathiazole.

Folic acid was assayed as Lactobacillus casei factor. The response curve of the assay organism to extracts of every strain of Staphylococcus examined was the same; but it differed from the response to known forms of folic acid. The active material had little growth-promoting activity for Leuconostoc citrovorum or for Streptococcus faecalis. Washed suspensions of Staphylococcus lactis $2102 \mathrm{R}$ formed about 10 times as much folic acid as the sensitive parent strain (2102) from glucose, $p$-aminobenzoate and glutamate; the sulphonamide-resistant substrain $(2102 \mathrm{R})$ also formed more folic acid during growth. However, a second resistant $S$. lactis substrain (2102 R 2) formed little more folic acid than did the parent strain. S. aureus $\mathrm{R} 122$ synthesized an amount of folic acid similar to that formed by $S$. lactis 2102 R. With two other strains (S. aureus $\mathrm{H}$ and JHM) the synthesis of folic acid was not increased when resistance was acquired. Washed suspensions of all the sulphonamide resistant substrains were able to synthesize folic acid in the presence of higher concentrations of sulphathiazole than were the sensitive strains.

\section{INTRODUCTION}

The study of the properties of drug-resistant staphylococci is valuable because of the frequency with which such strains occur in clinical infections (Jawetz, 1956; Harington, 1957). Resistance to sulphonamides was chosen for investigation because there is more detailed knowledge about the biochemical mode of action of these drugs than is the case with many of the antibacterial agents used in chemotherapy (Woods, 1952; 1958). Such information directs attention to the metabolism of $p$-aminobenzoic acid and folic acid, and suggests that the development of resistance may be related to changes in the metabolism of these compounds. Some sulphonamide-resistant strains of bacteria produce greater amounts of $p$-aminobenzoic acid during growth than do their sensitive parent strains (MacLeod, 1940;

* Present address: Twyford Laboratories, Twyford Abbey Road, London, N.W. 10. 
Landy, Larkum, Oswald \& Streightoff, 1943) although this behaviour is not found in all cases of sulphonamide-resistance (Lemberg, Callaghan, Tandy \& Goldsworthy, 1948; Yaniv \& Davis, 1953). Lascelles \& Woods (1952) studied the biosynthesis of folic acid (Lactobacillus casei factor) by Staphylococcus lactis 2102 and a sulphonamide-resistant substrain $2102 \mathrm{R}$. Folic acid was synthesized by washed suspensions of these organisms in a buffered solution of glucose + glutamate $+p$-aminobenzoate. In this mixture, and during growth, the sulphonamide-resistant strain synthesized about ten times as much folic acid as did the parent strain, and this synthesis was less sensitive to inhibition by sulphathiazole than was the synthesis by the parent strain.

In the present work, the synthesis of folic acid and of $p$-aminobenzoic acid in several strains of staphylococci has been examined to establish whether changes in the biosynthesis of $p$-aminobenzoic acid and/or folic acid generally accompany the development of resistance to sulphonamides.

\section{METHODS}

Organisms. Staphylococcus aureus strain JHM was isolated from a boil by Dr J. H. Marshall in this laboratory; from this a substrain (JHMR) was developed which was resistant to sulphathiazole. Strain H was the 'Oxford staphylococcus' (NCTC 6571); strain HR 2 was a sulphonamide-resistant substrain developed from it by Dr June Lascelles. Strain R 122 was a sulphonamide-resistant strain isolated from a patient by the Public Health Laboratory Service, Oxford. The sensitivities of these strains to sulphathiazole are shown in Table 1.

Table 1. Relative resistance to sulphathiazole of various strains of staphylococci

Organisms (about $10^{5}$ ) were incubated for $50 \mathrm{hr}$ at $37^{\circ}$ in medium $\mathrm{B}$ (5 ml.) containing various concentrations of sulphathiazole, in tubes $(150 \times 19 \mathrm{~mm}$.) sloped at about $5^{\circ}$ above the horizontal.

\begin{tabular}{|c|c|c|}
\hline Organism & $\begin{array}{l}\text { Highest concn. of } \\
\text { sulphathiazole } \\
\text { permitting growth } \\
\text { (M) }\end{array}$ & $\begin{array}{c}\text { Relative } \\
\text { resistance } \\
\text { compared } \\
\text { with } \\
\text { parent } \\
\text { strain }\end{array}$ \\
\hline $\begin{aligned} \text { Staphylococcus lactis } & 2102 \\
& 2102 \mathrm{R} \\
& 2102 \mathrm{R2}\end{aligned}$ & $\begin{array}{r}10^{-5} \\
5 \times 10^{-4} \\
5 \times 10^{-4}\end{array}$ & $\begin{array}{l}- \\
50 \\
50\end{array}$ \\
\hline $\begin{array}{l}S . \text { aureus } \mathrm{JHM} \\
\text { JHMR }\end{array}$ & $\begin{array}{r}5 \times 10^{-8} \\
10^{-4}\end{array}$ & $\overline{20}$ \\
\hline $\begin{array}{l}S . \text { aureus म } \\
\text { HR } 2\end{array}$ & $\begin{array}{r}5 \times 10^{-8} \\
10^{-3}\end{array}$ & $\overline{200}$ \\
\hline S. aureus $\mathrm{R} 122$ & $5 \times 10^{-4}$ & $\begin{array}{l}\text { Resistant } \\
\text { when } \\
\text { isolated }\end{array}$ \\
\hline
\end{tabular}

Staphylococcus lactis 2102 was a laboratory strain, previously called $S$. aureus 2102 by Lascelles \& Woods (1952). The organism formed golden coloured colonies on solid media, but it was coagulase negative and did not ferment mannitol. In these respects and in the production of acid and not acetoin from glucose it resembled more closely the characters ascribed to $S$. lactis n.sp. by Shaw, Stitt \& Cowan (1951). 
Strains $2102 \mathrm{R}$ and $2102 \mathrm{R} 2$ were sulphonamide-resistant substrains of 2102 , the former developed by Dr June Lascelles.

All resistant substrains were obtained by serial subculture of the respective parent strains in lots of medium $\mathbf{B}+$ increasing concentrations of sulphathiazole. At each stage, a set of tubes containing a serial 1/2 dilution of sulphathiazole was inoculated from the tube of the preceding series containing the highest concentration of sulphathiazole which permitted growth in 2-3 days. The resistant strain was finally plated out and an isolated colony selected. Resistance developed more readily when only a small increment of concentration of sulphathiazole was used at each subcultivation after a short period of incubation.

Escherichia coli 273/384. (ATCC 9723a) was an X-ray induced mutant which required $p$-aminobenzoic acid for growth.

Stock cultures of all the above organisms were maintained on slopes of tryptic meat agar, subcultured monthly, incubated for $15 \mathrm{hr}$ at $37^{\circ}$ and stored at $2^{\circ}$.

Streptococcus faecalis R (ATCC 8043); Lactobacillus casei (helveticus) (ATcC 7469); and Leuconostoc citrovorum (Pediococcus cerevisiae; ATCC 8081) were maintained in Tryptose glucose agar stab cultures, subcultured monthly, incubated $24 \mathrm{hr}$ at $37^{\circ}$ and stored at $2^{\circ}$. With all organisms, four subcultures were taken at monthly intervals; each subculture was used as source of further subcultures.

Medium. All strains of staphylococci were grown in medium B which was based on acid-hydrolysed casein and modified from that of Lascelles \& Woods (1952) by the replacement of DL-cysteine by L-cysteine hydrochloride $(100 \mathrm{mg} . / \mathrm{l}$.) and by increasing the amount of $\mathrm{KH}_{2} \mathrm{PO}_{4}$ to $700 \mathrm{mg}$./l. and of $\mathrm{Na}_{2} \mathrm{HPO}_{4} 12 \mathrm{H}_{2} \mathrm{O}$ to $10 \mathrm{~g}$./l. This medium was prepared at double strength in glass-distilled water, and was brought to the desired volume with glass-distilled water and other additions before autoclaving for $7 \mathrm{~min}$. at $115^{\circ}$. Glucose solutions were autoclaved separately.

Experiments with suspensions of organisms. Medium B (25 ml. after all additions) in a $180 \times 32 \mathrm{~mm}$. tube was inoculated with about $2 \times 10^{8}$ organisms from an agar slope. The tube was incubated for 14-16 hr at $37^{\circ}$, the tube being sloped at about $5^{\circ}$ above the horizontal. Organisms were centrifuged and washed once with $0.02 \mathrm{M}$-phosphate buffer ( $\mathrm{pH} 6.8$ or $7 \cdot 4 ; 25 \mathrm{ml}$.). Because of the large inoculum used the growth of none of the strains of staphylococci was inhibited by sulphathiazole at the highest concentration used (mM).

Mixture $\mathbf{F}$ for experiments on the synthesis of folic acid by suspensions of organisms was that described by Lascelles $\&$ Woods (1952). It contained glucose, glutamate and $p$-aminobenzoic acid in phosphate buffer and was prepared at double strength and subsequently brought to the desired volume with glass-distilled water and other additions.

Microbiological assay of p-aminobenzoic acid. The organism used was Escherichia coli $273 / 384$, a mutant which needs $p$-aminobenzoic acid as a nutrient. The nutrient requirement is decreased by the presence of methionine, xanthine, thymine and vitamin $\mathrm{B}_{12}$ (Lampen, Jones \& Roepke, 1949; de Haan, 1950); it was shown in the present work that these compounds were not present in material under assay in amounts sufficient to interfere. The minimal medium of Davis \& Mingioli (1950) was used, modified by autoclaving the glucose in the medium. The sample, or standard amount of $p$-aminobenzoate, was added to double strength medium $(2.5 \mathrm{ml}$.) in $150 \times 19 \mathrm{~mm}$. tubes, and the volume was made to $4.9 \mathrm{ml}$. with water. After 
autoclaving for $7 \mathrm{~min}$. at $115^{\circ}$ the medium was inoculated with a suspension $(0 \cdot 1 \mathrm{ml}$; about $2 \times 10^{6}$ organisms) of Escherichia coli $273 / 384$ from an agar slope. The tubes were incubated sloped at about $5^{\circ}$ above the horizontal for $48 \mathrm{hr}$ at $37^{\circ}$; growth was assessed in an EEL photoelectric colorimeter (Evans Electroselenium Co. Ltd, Halstead, Essex) with a neutral density filter; the uninoculated medium being used to give the zero setting. Each assay included a standard response curve for $p$-aminobenzoate and each sample was assayed at two or three dilutions; every tube was set up in duplicate. The effective range of the assay was from 5 to $50 \mu \mu$ moles $p$-aminobenzoate, with an accuracy of $\pm 20 \%$ (Fig. 1).

The precision of the assay was found by determining the statistic $\mathrm{C}$, which measures the reliability of the assay slope (Bliss, 1956); a value of 1.03 was obtained. The more nearly $\mathrm{C}$ approaches unity the more precise is the assay, while an assay with a value of $\mathrm{C}$ greater than 2 is of little value. The validity of the assumptions that are made in this factorial analysis, namely, a linear relation between the response and the logarithm of the dose, and agreement in slope of the response curve for different samples, was confirmed statistically.

Samples for assay were obtained by heating the cultures of staphylococci for 5 min. at $100^{\circ}$ and removing the organisms by centrifugation; the supernatant fluids were usually diluted tenfold. When sulphathiazole was also present in the samples it was separated from $p$-aminobenzoate by descending chromatography (12 $\mathrm{hr}$ at room temperature) on Whatman no. I paper, with $n$-butanol saturated with water as solvent. The position of $p$-aminobenzoate on the chromatograms was found by running a marker strip which was cut off and examined by bioautography with Escherichia coli $\mathbf{2 7 3 / 3 8 4}$. The part of the chromatogram that contained $p$-aminobenzoic acid was eluted with water. Recovery of known amounts of $p$-aminobenzoate was only about $50 \%$.

Assay of folic acid. Material for assay of folic acid was prepared by autoclaving the reaction mixture (including organisms) for $10 \mathrm{~min}$. at $115^{\circ}$ with an equal volume of the appropriate assay medium at double strength. The supernatant fluid after centrifugation was used for the assay of various forms of folic acid by using three assay organisms.

The technique of Lascelles \& Woods (1952) was used for assay of Lactobacillus casei factor. This assay organism responds to pteroylglutamic acid, pteroyltriglutamic acid and leucovorin ( $\mathbf{N}^{5}$-formyltetrahydropteroylglutamic acid), but extracts of all the staphylococci tested gave response curves which diverged in a similar manner from the response curve to pteroylglutamic acid (Fig. 2). Consequently the amounts of $L$. case $i$ factor present in extracts was assessed against a reference extract as described by Lascelles \& Woods (1952).

The assay for Leuconostoc citrovorum factor was that of Sauberlich \& Baumann (1948) with the modifications introduced by Lascelles \& Woods (1952). Synthetic leucovorin was used as a standard. L. citrovorum does not respond to pteroylglutamate and other unreduced forms of folic acid.

Streptococcus faecalis $\mathrm{R}$ responds to pteroic acid and $\mathbf{N}^{10}$-formylpteroic acid (rhizopterin) as well as to pteroylglutamic acid and leucovorin. The medium was that of Rabinowitz \& Snell (1947). Extract or rhizopterin solution was added to doublestrength medium $(2.5 \mathrm{ml}$.) in $125 \times 16 \mathrm{~mm}$. tubes, the volume brought to $4.4 \mathrm{ml}$. with water and the tubes were autoclaved for $7 \mathrm{~min}$. at $115^{\circ}$; pyridoxal $(0.1 \mathrm{ml}$., 
$2.5 \mu \mathrm{M})$ sterilized by Seitz-filtration was then added. The inoculum was derived from a fresh stab culture in Tryptose glucose agar which was subcultured into Tryptose glucose broth and incubated $15 \mathrm{hr}$ at $37^{\circ}$; this culture was diluted 1/100 and each tube of the assay inoculated with $0.5 \mathrm{ml}$. (about $2 \times 10^{7}$ organisms); for incubation the tubes were vertical in air for $40-44 \mathrm{hr}$ at $37^{\circ}$. Standards containing rhizopterin (0.1-1.0 m $\mu$ moles) were set up in each assay; the curves for the response of the assay organism to synthetic rhizopterin and to staphylococcal extracts were similar (Fig. 3). The effective range of the assay was from 1 to $5 \mu \mu$ moles rhizopterin; the values for $\boldsymbol{S}$. faecalis-factor activity are expressed in terms of this compound.

Chemicals. Pteroylglutamic acid and leucovorin were gifts from Dr E. L. R. Stokstad and rhizopterin was provided by Dr K. Folkers. Sulphathiazole was a gift from May \& Baker Ltd, Dagenham, Essex.

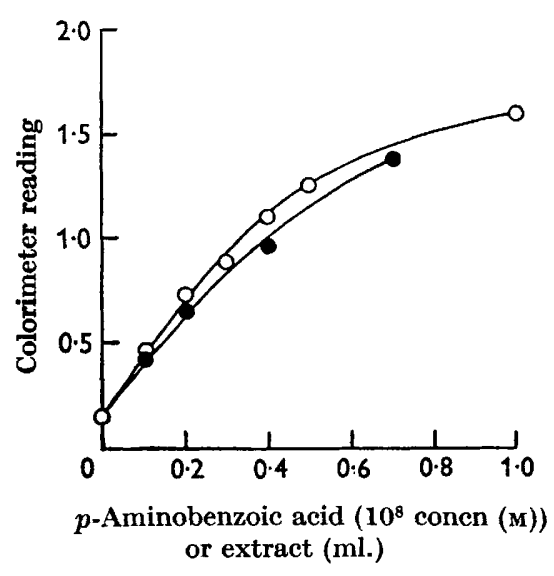

Fig. 1

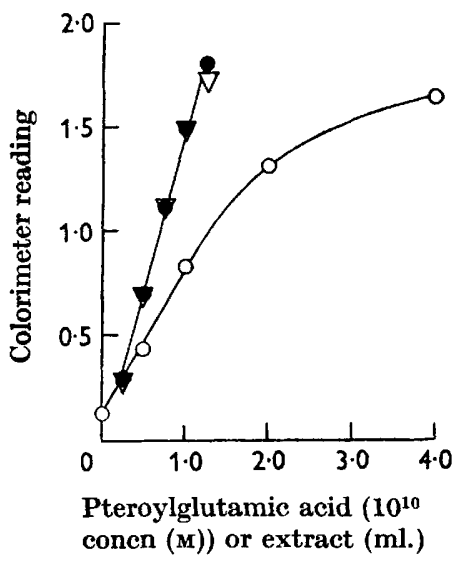

Fig. 2

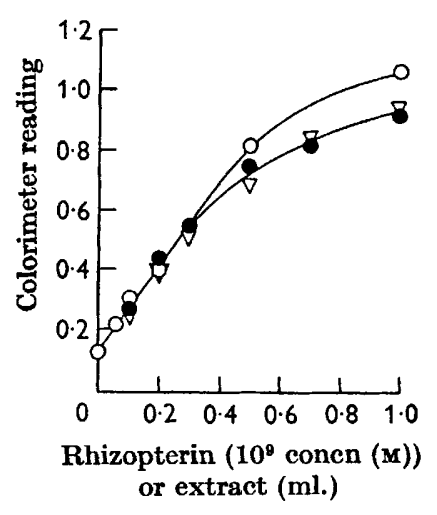

Fig. 3

Fig. 1. Response of Escherichia coli $273 / 384$ to $p$-aminobenzoic acid and to a culture filtrate (of Staphylococcus aureus HR2) prepared as described in Methods. $O=p$-aminobenzoic acid; $=$ culture filtrate. The assay organism was incubated at $37^{\circ}$ for $48 \mathrm{hr}$ before its growth was assessed.

Fig. 2. Response of Lactobacillus casei to pteroylglutamic acid and to extracts of Staphylococcus aureus $\mathrm{B}$ and $\mathrm{HR2}$ prepared as described in Methods. $\mathrm{O}=$ pteroylglutamic acid; $\nabla=S$. aureus $\mathrm{H}$ extract; $\bigcirc=S$. aureus $\mathrm{HR} 2$ extract. The assay organism was incubated at $37^{\circ}$ for $20 \mathrm{hr}$ before its growth was assessed.

Fig. 3. Response of Streptococcus faecalis $\mathrm{R}$ to rhizopterin and to extracts of Staphylococcus aureus $\mathrm{H}$ and HR 2, prepared as described in Methods. $O=$ Rhizopterin; $\nabla=S$. aureus $\mathrm{H}$ extract; $=S$. aureus HR2 extract. The assay organism was incubated at $37^{\circ}$ for $40 \mathrm{hr}$ before its growth was assessed.

\section{RESULTS}

\section{Synthesis of p-aminobenzoic acid}

The synthesis of $p$-aminobenzoic acid during growth of the various strains of Staphylococcus in medium B was investigated in the presence and in the absence of sulphathiazole. Incubation was for 14-16 hr, by which time growth had just reached the end of the logarithmic phase. The most striking feature of the results (Table 2) for growth in the absence of sulphathiazole was the very high synthesis of 
$p$-aminobenzoic acid by Staphylococcus aureus R 122 ; its concentration in the medium after growth was just over $10 \mu \mathrm{M}$. The resistant strains of $S$. aureus JHM and $\mathrm{H}$ did not synthesize appreciably different amounts of $p$-aminobenzoic acid than their parent (sensitive) strains. Still less $p$-aminobenzoic acid was synthesized by $\boldsymbol{S}$. lactis 2102 ; in one of its resistant substrains (2102 $\mathrm{R} 2)$ the amount of synthesis was the same as for the parent, whereas in the other substrain (2102 R) there was a five-fold increase. However, the extent of synthesis by strain $2102 \mathrm{R}$ was no greater than was found for the sensitive strains of $S$. aureus.

Possibly the remainder of the resistant strains synthesized greater amounts of $p$-aminobenzoate than their sensitive parent strains only in the presence of sulphonamides. Organisms were therefore cultured as before but in the presence of sulphathiazole; $p$-aminobenzoate and sulphathiazole were separated in the extracts by chromatography and the amount of $p$-aminobenzoic acid was assayed (Table 2). However, sensitive and resistant pairs of strains of Staphylococcus aureus synthesized rather similar amounts of $p$-aminobenzoate. Although the accuracy of the figures is low because of the poor recovery of $p$-aminobenzoate from the chromatograms, a ten-fold or greater difference in synthesis of $p$-aminobenzoate between sensitive and resistant strains (such as would be required to explain resistance) would have been detected easily.

\section{Synthesis of folic acid}

Lactobacillus casei factor. After harvesting from medium B, the content of Lactobacillus case $i$ factor was about the same in all of the sulphonamide-sensitive strains (Table 3). In two of the resistant strains (Staphylococcus lactis $2102 \mathrm{R}, S$. aureus $\mathrm{R} 122$ ) there was about five times as much factor, but in the other three resistant strains little more factor was present than in the corresponding parent strain.

Table 2. Synthesis of p-aminobenzoic acid by sensitive and resistant strains of staphylococci

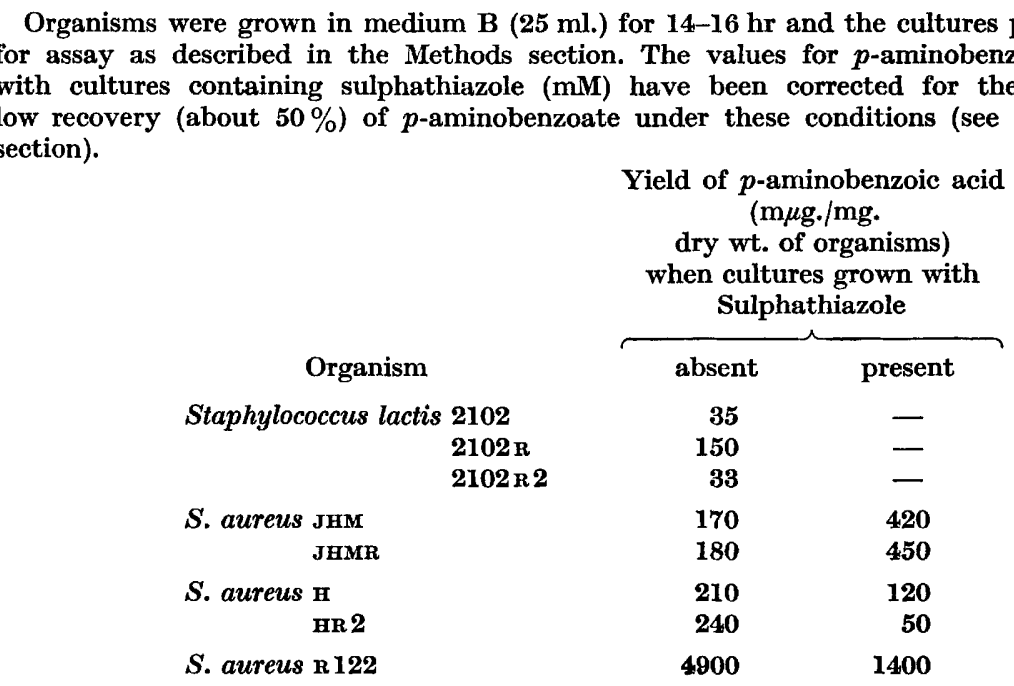


Table 3. Content of and synthesis of Lactobacillus casei factor

by suspensions of staphylococci

\begin{abstract}
'Normal' staphylococci were harvested from medium B(25 ml.) after growth for 14-16 hr. For 'depleted' organisms the medium also contained sulphathiazole ( $5 \mu \mathrm{M}$ for sensitive strains; $\mathbf{5 0} \mu \mathrm{m}$ for resistant strains). The content of Lactobacillus casei factor was measured initially after suspension in mixture F. 'Depleted' organisms $(0 \cdot 2 \mathrm{mg}$. dry wt./ml.) were incubated at $37^{\circ}$ for $5 \mathrm{hr}$ in mixture $\mathrm{F}$ (final volume, $2.5 \mathrm{ml}$.) upright in $130 \times 16 \mathrm{~mm}$. tubes and the content of $L$. casei factor of the whole suspension again assayed.

L. casei factor is expressed below as pterolyglutamic acid.
\end{abstract}

L. casei factor (m $\mu \mathrm{g} . / \mathrm{mg}$. dry wt. organisms)

\begin{tabular}{|c|c|c|c|}
\hline \multirow[b]{2}{*}{ Organism } & \multirow[b]{2}{*}{$\begin{array}{l}\text { 'Normal' } \\
\text { organisms: } \\
\text { Initial }\end{array}$} & \multicolumn{2}{|c|}{ 'Depleted' organisms: } \\
\hline & & Initial & $\begin{array}{c}\text { After } \\
\text { incubation in } \\
\text { mixture } \mathbf{F}\end{array}$ \\
\hline $\begin{aligned} \text { Staphylococcus lactis } & 2102 \\
& 2102 \mathrm{R} \\
& 2102 \mathrm{R} 2\end{aligned}$ & $\begin{array}{r}35 \\
200 \\
50\end{array}$ & $\begin{array}{l}3 \\
8 \\
4\end{array}$ & $\begin{array}{r}18 \\
110 \\
30\end{array}$ \\
\hline $\begin{array}{l}\text { S. aureus JHM } \\
\text { JHMR }\end{array}$ & $\begin{array}{l}\mathbf{3 0} \\
\mathbf{3 3}\end{array}$ & $\begin{array}{l}4 \\
6\end{array}$ & $\begin{array}{l}10 \\
15\end{array}$ \\
\hline $\begin{array}{l}\text { S. aureus } \mathrm{H} \\
\qquad \mathrm{HR} 2\end{array}$ & $\begin{array}{l}28 \\
28\end{array}$ & $\begin{array}{l}6 \\
6\end{array}$ & $\begin{array}{l}13 \\
12\end{array}$ \\
\hline S. aureus $\mathrm{R} 122$ & 130 & 8 & 80 \\
\hline
\end{tabular}

Lascelles \& Woods (1952) found that synthesis of $L$. casei factor by washed suspensions of $S$. lactis 2102 and $2102 \mathrm{R}$ occurred only in organisms which contained initially only small amounts of the factor; such organisms ('depleted') were obtained by growth in the presence of sub-inhibitory concentrations of sulphathiazole. In the present work normal organisms of all strains showed very slight synthesis of the factor. The finding of Lascelles \& Woods (1952) that 'depleted' S. lactis $2102 \mathrm{R}$ synthesized about ten times as much $L$. case $i$ factor as did its parent strain was confirmed (Table 3). S. lactis $2102 \mathrm{R} 2$, the other resistant substrain, also synthesized significantly more of the factor than did its parent, though the increase (1.7-fold) was much less than with strain $2102 \mathrm{R}$. $S$. aureus $\mathrm{R} 122$, like $S$. lactis $2102 \mathrm{R}$, had a relatively high content of factor after growth in medium B; suspensions of 'depleted' organisms also synthesized a comparatively large amount in mixture $\mathbf{F}$ (Table 3). No (sensitive) parent strain was available for comparison in this case. The resistant strains of $S$. aureus JHM and $\mathrm{H}$, even after depletion, synthesized no more factor than the small amount formed by their parent strains. Incubation of the suspensions for longer periods in mixture $F$, growth of cultures in a richer medium, and treatment with higher concentrations of sulphathiazole (up to $1 \mathrm{~mm}$ ) during growth did not appreciably increase the synthesis of the $L$. case $i$ factor by these strains.

Lascelles \& Woods (1952) found that the synthesis of Lactobacillus casei factor in mixture F by Staphylococcus lactis 2102 and $2102 \mathrm{R}$ was inhibited by sulphathiazole. Synthesis by the resistant strain was eight times more resistant to sulphathiazole than was that of the parent strain; the difference was 50-fold when growth was the criterion of sensitivity. It was pointed out that such a comparison was only realistic when it is known that all the substances necessary for the synthesis of the 
Table 4. Inhibition by sulphathiazole of the synthesis of Lactobacillus casei factor by staphylococci

'Depleted' staphylococci were obtained (as in Table 3) and incubated in mixture F (as in Table 3 ) in the presence of the stated concentrations of sulphathiazole. $p$-Aminobenzoic acid was $10 \mu \mathrm{M}$ throughout.

(20), etc. is the approximate percentage inhibition as compared with the control without sulphathiazole.

\begin{tabular}{|c|c|c|c|c|c|}
\hline \multirow[t]{3}{*}{ 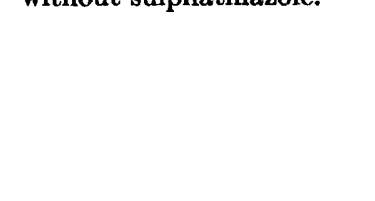 } & \multicolumn{5}{|c|}{ Sulphathiazole (M) } \\
\hline & 0 & $10^{-6}$ & $10^{-5}$ & $10^{-4}$ & $10^{-3}$ \\
\hline & \multicolumn{5}{|c|}{$\begin{array}{l}\text { L. casei factor formed after } 5 \mathrm{hr} \text { in mixture } \mathrm{F} \\
(\mathrm{m} \mu \mathrm{g} \cdot * / \mathrm{mg} \text {. dry wt. organisms) }\end{array}$} \\
\hline $\begin{array}{r}\text { Staphylococcus lactis } 2102 \mathrm{R} \\
2102 \mathrm{R2}\end{array}$ & $\begin{array}{r}160 \\
44\end{array}$ & $\begin{array}{r}150(10) \\
40(10)\end{array}$ & $\begin{array}{l}64(60) \\
18(60)\end{array}$ & $\begin{array}{l}9(90) \\
5(90)\end{array}$ & $\overline{0(100)}$ \\
\hline $\begin{array}{l}\text { S. aureus JHM } \\
\text { JHMR }\end{array}$ & $\begin{array}{l}5 \\
8\end{array}$ & $\begin{array}{l}6(0) \\
7(10)\end{array}$ & $\begin{array}{l}3(40) \\
5(30)\end{array}$ & $\begin{array}{l}2(70) \\
5(40)\end{array}$ & $\begin{array}{l}0(100) \\
3(70)\end{array}$ \\
\hline $\begin{array}{l}S . \text { aureus } \mathrm{H} \\
\mathrm{HR2}\end{array}$ & $\begin{array}{l}7 \\
8\end{array}$ & $\begin{array}{l}6(20) \\
7(10)\end{array}$ & $\begin{array}{l}5(80) \\
6(20)\end{array}$ & $\begin{array}{l}4(50) \\
7(10)\end{array}$ & $\begin{array}{l}0(100) \\
4(50)\end{array}$ \\
\hline
\end{tabular}

* Expressed as pteroylglutamic acid.

factor by suspensions of organisms are present in optimal amounts. In the present work the sensitivity of the synthesis of $L$. casei factor to inhibition by sulphathiazole in suspensions of $S$. lactis $2102 \mathrm{R} 2$ resembled that of $S$. lactis $2102 \mathrm{R}$ (Table 4 ). In the experiments with Staphylococcus aureus JHM and $\mathrm{H}$, and their resistant substrains, the amounts of the $L$. case $i$ factor synthesized were low, but there was a progressive inhibition of this synthesis by increasing concentrations of sulphathiazole and the resistant strains were less sensitive to this inhibition than were the parent strains (Table 4).

Table 5. Content and synthesis of Streptococcus faecalis factor by suspensions of staphylococci

Normal and depleted staphylococci were obtained as in Table 3 and suspended in Mixture F. After removing a sample for assay of the initial $S$. faecalis factor, the organisms were incubated in mixture $F$ (as in Table 3 ) and re-assayed for $S$. faecalis factor. The values in brackets were obtained after acid hydrolysis of the samples (see text).

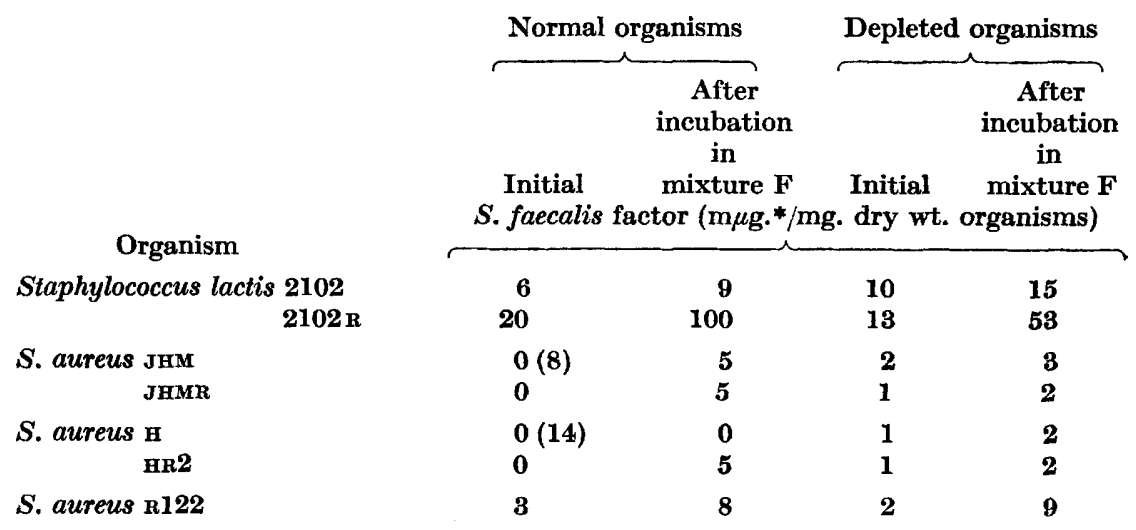

\footnotetext{
* Expressed in terms of $\mathrm{N}^{10}$-formylpteroic acid.
} 
Streptococcus faecalis factor. A possible reason for the apparently low content of folic acid in extracts of Staphylococcus aureus JHM and $\mathrm{H}$ and their resistant substrains is that some of the folic acid might be present in a form to which Lactobacillus casei does not respond. Streptococcus faecalis responds to two compounds of the folic acid group, pteroic acid and rhizopterin, which are not active for $L$. casei; these compounds do not contain a glutamic acid residue. Results of determinations of the initial amounts (in organisms grown in medium B) of factors active with $S$. faecalis, and the amounts synthesized by washed suspensions are shown in Table 5 . Only in the case of Staphylococcus lactis $2102 \mathrm{R}$ was there a striking synthesis by washed suspensions. The very low activity of most of the extracts of 'normal' organisms is noteworthy, since all the organisms had activity for L. casei (Table 3). Since there was good recovery of added rhizopterin from staphylococcal extracts it was unlikely that these extracts inhibited the assay organism. Most probably the folic acid in the extracts was a form to which $S$. faecalis did not respond although L. case $i$ did. One such compound is pteroyltriglutamic acid, which on a molar basis is ten times as active for $L$. case $i$ as for $S$. faecalis (Jukes \& Stokstad, 1948). Extracts of two of the sensitive staphylococci were diluted with an equal volume of $\mathrm{N}-\mathrm{HCl}$, autoclaved at $115^{\circ}$ for $10 \mathrm{~min}$. and neutralized with $\mathrm{N}-\mathrm{NaOH}$; the activity of the extracts was considerably increased (Table 5). A quantitative conversion of material present in the extracts into factors active for $\boldsymbol{S}$. faecalis was not attempted.

Leuconostoc citrovorum factor. Lascelles \& Woods (1952) found that typical extracts of Staphylococcus lactis $2102 \mathrm{R}$ were much more active in supporting the growth of Lactobacillus casei than the growth of Leuconostoc citrovorum. This was confirmed in the present work, and it was also found that none of the extracts of any of the strains of Staphylococcus aureus (whether sensitive or resistant to sulphathiazole) had detectable activity as a growth factor for $L$. citrovorum.

\section{DISCUSSION}

The resistance of Staphylococcus aureus $\mathrm{R} 122$ to sulphonamides may be due at least in part to the synthesis of relatively large amounts of $p$-aminobenzoic acid. This organism synthesized twenty times as much $p$-aminobenzoic acid as did $S$. aureus strains JMH and $\mathrm{H}$, and its growth was about one hundred times less sensitive to inhibition by sulphathiazole. A better comparison would be with a sensitive substrain of $S$. aureus $\mathrm{R} 122$ but this was not obtained. $S$. lactis $2102 \mathrm{R}$ showed a fourfold increase in $p$-aminobenzoate synthesis over the parent strain while its resistance to sulphathiazole had increased 50-fold. In other work where an increased synthesis of $p$-aminobenzoic acid was accompanied by sulphonamide-resistance there was not always a proportional relation between increase in $p$-aminobenzoate synthesis and change in resistance. For instance, the sulphonamide-resistant staphylococci described by Landy et al. (1943) synthesized about seventy times more $p$-aminobenzoic acid than did the parent strains, but showed a thousand-fold decrease in sensitivity to the drug.

All the staphylococcal strains examined here produced material which replaced folic acid for growth of Lactobacillus casei but which gave a response curve differing from that to synthetic pteroylglutamic acid (or other forms of folic acid available for testing; Lascelles \& Woods, 1952). This $L$. casei factor may be a conjugate of folic acid with glutamic acid because it was not active in supporting the growth of 
Streptococcus faecalis (which does not respond to known conjugates) in a medium deficient of folic acid, though it did support growth after hydrolysis with acid. Staphylococcus lactis $2102 \mathrm{R}$, during growth and when incubated with $p$-aminobenzoic acid + glutamate + glucose, did form appreciable quantities of material which supported the growth of $S$. faecalis, and which gave a response curve resembling that to synthetic rhizopterin ( $\mathrm{N}^{10}$-formylpteroic acid). Possibly this response of $S$. faecalis represents the inefficient utilization of the $L$. casei factor synthesized by $S$. lactis $2102 \mathrm{R}$. It seems more probable, however, that this $S$. faecalis factor was formed by the staphylococcus in addition to the $L$. case $i$ factor; extracts of $S$. aureus $\mathrm{R} 122$ which were also rich in $L$. casei factor had low activity for $S$. faecalis.

Only Staphylococcus lactis $2102 \mathrm{R}$ and $S$. aureus $\mathrm{R} 122$ synthesized much more Lactobacillus casei factor than did the sulphonamide-sensitive strains of staphylococci either during growth or when suspended in a solution containing $p$-aminobenzoic acid + glutamate + glucose (mixture F). Nevertheless, in all the resistant strains the synthesis of $L$. case $i$ factor in this solution was less sensitive to inhibition by sulphathiazole.

Sevag \& Ishii (1958) gave evidence for a changed pathway of folic acid synthesis induced by sulphathiazole. Growth of a $p$-aminobenzoate-requiring mutant of Escherichia coli in the presence of sulphathiazole enabled the organisms to synthesize folic acid from 2-amino-4-hydroxy-6-carboxypterin and $p$-aminobenzoic acid. This ability was also shown by resistant organisms grown in the presence or absence of sulphathiazole, but not by sensitive organisms grown in the absence of sulphathiazole. It has not been shown whether this new pathway in Escherichia coli is less sensitive to inhibition by sulphathiazole.

Growth of organisms in the presence of sulphathiazole was necessary in the present work in order to obtain appreciable synthesis of folic acid by washed suspensions of organisms. The organisms were depleted of folic acid by growing with sulphathiazole; (they may accumulate precursors of folic acid); only glucose was required as an essential for synthesis of folic acid by these suspensions. Lascelles \& Woods (1952) found that addition of 2-amino-4-hydroxy-6-formylpterin increased synthesis of folic acid by Staphylococcus lactis 2102 and $2102 \mathrm{R}$ in mixture F, but it was rather less effective than a mixture of amino acids which approximately doubled the synthesis of folic acid; other pterins, including 2-amino-4-hydroxy-6-carboxypterin, had no effect. There is however no evidence that sulphathiazole alters the pathway of folic acid synthesis in Staphylococcus. Although S. lactis 2102 R synthesizes about ten times more folic acid than its parent strain, it does so from the same exogenous substrates, and the difference in the amount of folic acid formed is still shown during growth in the absence of sulphathiazole.

In general the results of the present work suggest that even within a group of closely related organisms there may be more than one mechanism by which resistance to sulphonamides is achieved, and that even two mechanisms may exist in the same organism. Thus one resistant strain (Staphylococcus aureus $\mathrm{R} 122$ ) was able to synthesize abnormally large amounts of $p$-aminobenzoic acid and was also able to convert this to folic acid more efficiently than were sensitive strains. Another strain ( $S$. lactis $2102 \mathrm{R}$ ) showed some (though less marked) increase in ability to synthesize $p$-aminobenzoic acid as compared with the parent (sensitive) strain, and 
had a more marked ability than had $S$. aureus $\mathrm{R} 122$ to form folic acid. The other resistant strains ( $S$. aureus JHMR and HR 2 ; $S$. lactis $2102 \mathrm{R} 2$ ) did not show significantly greater ability to synthesize $p$-aminobenzoic acid nor increased ability to convert it to folic acid. It seems likely, therefore, that yet another mechanism of resistance may operate in these strains. Some of these possibilities will be considered in the next paper (White \& Woods, 1965).

One of us (P.J.W.) is indebted to the Medical Research Council for a training scholarship held during the period of this work.

\section{REFERENCES}

Burss, C. J. (1956). The calculation of Microbial Assays. Bact. Rev. 20, 243.

Davis, B. D. \& Mingioli, E. S. (1950). Mutants of Escherichia coli requiring methionine or vitamin $B_{12}$. J. Bact. 60, 17.

DE HAAN, P. G. (1950). Het Werkingsmechanisme van Sulfanilamide. Thesis. University of Utrecht.

Harington, Sir C. (1957). In Drug Resistance in Micro-organisms. Ed. G. E. W. Wolstenholme and C. M. O'Connor, p. 1. London: J. and A. Churchill Ltd.

JAwetz, E. (1956). Antimicrobial chemotherapy. Annu. Rev. Microbiol. 10, 85.

Jukes, T. H. \& Stokstad, E. L. R. (1948). Pteroylglutamic acid and related compounds. Physiol. Rev. 28, 51.

LAMpen, J. O., Jones, M. J. \& RoEPKe, R. R. (1949). Mutant strains of Escherichia coli unable to synthesize $p$-aminobenzoic acid. J. biol. Chem. 180, 423.

Landy, M., Larkum, N. W., Oswaid, E. J. \& Streightoff, F. (1943). Increased synthesis of $p$-aminobenzoic acid associated with the development of sulfonamide resistance in Staphylococcus aureus. Science, 97, 265.

Lascelues, June \& Woods, D. D. (1952). The synthesis of 'folic acid' by Bacterium coli and Staphylococcus aureus and its inhibition by sulphonamides. Br. J. exp. Path. 33, 288.

Lemberg, R, Callaghan, J. P., Tandy, D. E. \& Goldsworthy, N. E. (1948). Production of aminobenzoic acids by bacteria resistant to sulphonamides. Aust. J. exp. Biol. med. Sci. 26, 9.

MacLEon, C. M. (1940). The inhibition of the bacteriostatic action of sulphonamide drugs by substances of animal and bacterial origin. J. exp. Med. 72, 217.

Rabinowitz, J. C. \& SNerd, E. E. (1947). The vitamin B $_{6}$ group. II. An improved method for assay of vitamin $B_{6}$ with Streptococcus faecalis. J. biol. Chem. 169, 631 .

Sauberlich, H. E. \& Baumann, C. A. (1948). A factor required for the growth of Leuconostoc citrovorum. J. biol. Chem. 176, 165.

SevaG, M. G. \& IshiI, K. (1958). Drug-induced reversible and irreversible enzyme alterations underlying drug-resistance. Proc. Roy. Soc. B, 149, 63.

Shaw, C., StrtT, J. M. \& Cowan, S. T. (1951). Staphylococci and their classification. J. gen. Microbiol. 5, 1010.

WHITE, P. J. \& Woods, D. D. (1965). Biochemical properties of staphylococci sensitive and resistant to sulphonamides. J. gen. Microbiol. 40, 255.

Woods, D. D. (1952). The function of folic acid and related growth factors in the metabolism of micro-organisms. In Symposium on Microbial Metabolism, p. 86. 2nd Int. Congr. Biochem., Paris.

Woons, D. D. (1958). Biosynthesis and breakdown of folic acid. In Symposium on Vitamin Metabolism, p. 87. 4th Int. Congr. Biochem., Vienna.

Yaniv, H. \& Davis, B. D. (1953). The relation between sulphonamide resistance and $p$-aminobenzoic acid requirement. J. Bact. 66, 238. 